\title{
Formas de representação feminina nos teen chick lits: um estudo em torno d'O diário da princesa.
}

\section{Female ways of representation in the teen chick lits: a study around The Princess Diaries.}

Alleid Ribeiro Machado

Resumo: Este artigo trata das formas de representação do feminino que aparecem na contemporaneidade em livros voltados para o público adolescente, como ocorre, por exemplo, em O diário da princesa (2000), de Meg Cabot. Nesse romance, pode-se observar a construção e o reforço de ideais de beleza e de comportamento que se abrem para questões de gênero, corpo e sexualidade ao estabelecer padrões estigmatizados, sobretudo para as meninas em crescimento. A ideia é, em última instância, trazer a lume uma discussão em torno de um tipo de literatura denominada teen chick lit (do inglês, literatura de massa voltada para o público adolescente feminino) que, supostamente atrelada a alguns pressupostos da terceira onda feminista e à indústria cultural, tem veiculado a premissa insidiosa de empoderamento feminino.

Palavras-chave: teen chick lit; gênero; terceira onda feminista; empoderamento feminino.

Abstract: This paper deals with female ways of representation, which appear in the contemporaneity, in books turned to teenager audience, as it is going to occur in The Princess Diaries (2000), by Meg Cabot, for example. In this novel, we can observe the construction and the intensification around the ideal pattern of beauty and behavior, what are opened for issues around gender, body, and sexuality when they try to stablish stigmatized patterns, moreover, for girls under development. The idea is, at last, to bring to light the discussion around a kind of literature labeled by teen chick lit (mass literature aimed at teen female 
audience). Supposedly, this literature is linked to some assumptions related to the third-wave feminism and to the cultural industry which, insidiously, have conducted to the female empowerment.

Keywords: teen chick lit; gender; third-wave feminism; female empowerment. 


\section{Introdução}

Empoderar uma mulher significa fortalecê-la, dar-lhe poder, conscientizá-la de suas capacidades e competências; empoderar duas ou mais mulheres significa desenvolver a igualdade de gêneros em todos os ambientes onde elas sejam minoria. A ideia do empoderamento feminino hoje multiplica-se nas redes sociais e não é raro observar campanhas seguidas das palavras-chave (hashtags) \#empodereumamulher, \#empodereasmulheres, \#heforshe, \#elaspodem ou \#empoderamentofeminino, justamente incentivando mulheres a se conscientizarem de seus direitos e potencialidades e, assim, empoderarem suas companheiras, mães, amigas, irmãs.

A questão é que o início do século XXI é marcado por uma realidade sem fronteiras, de capitalismo irrestrito regido e orquestrado pela indústria cultural. Adorno e Horkheimer (2002) pensam essa realidade associando-a às artes. Para os autores, ela atuaria no sentido de neutralizar os aspectos críticos de uma obra artística, transformando-a em objeto comercial. Portanto, estabelecendo-se uma correlação entre as campanhas de paridade de gênero, empoderamento feminino e outras de cunho feminista em redes sociais como Facebook e Instagram e a indústria da literatura de massa, poder-se-ia afirmar que essas lutas são assimiladas pelo mercado editorial gerido pelo capital de forma intensa e direta ao colocar em pauta, em livros direcionados às mulheres, o feminismo e a ideia de empoderamento, mas a contrapelo, perpetuando estigmas de gênero, corpo e sexualidade.

A partir do entendimento desses fenômenos, este artigo busca problematizar um tipo de literatura de massa que veio a ser denominado chick lit e seu subgênero, teen chick lit, expressão em língua inglesa que se refere à literatura comercial direcionada ao público feminino - em particular, o termo teen identifica o público adolescente feminino -, em razão de observar-se que tais produções têm sido relacionadas ao feminismo, conforme indicam autoras como Angela McRobbie (2004), Suzanne Ferriss e Young Mallory (2006), não apenas por serem escritas 
por mulheres, mas principalmente por destacarem protagonistas supostamente libertas da dominação masculina.

De forma mais direta, toma-se como base de análise o romance $O$ diário da princesa (2000), de Meg Cabot. Nesse livro de confidencialidades, pode-se verificar a construção e o reforço dos ideais de beleza e de comportamento que se abrem para questões de gênero ao estabelecerem padrões estigmatizados, sobretudo para as meninas em crescimento. A ideia é, em última instância, trazer a lume uma discussão suscitada por uma literatura de massa que, atrelada a alguns pressupostos da terceira onda feminista e à indústria cultural, tem veiculado a premissa insidiosa de empoderamento feminino.

\section{Do movimento girlie ao teen chick lit: mídia e consumo}

Em termos genéricos, a sociedade do início do século XXI transformou-se sobremaneira 66 anos depois de Simone de Beauvoir (1949) lançar a sua mais célebre frase: "Não se nasce mulher, torna-se", que veio a ser a pedra de toque tanto para o feminismo quanto para os estudos de gênero. Admite-se hoje a existência de uma terceira vaga, também entendida como pós-feminismo, "que se identificaria mais com uma agenda liberal e individualista do que com objetivos coletivos e políticos, considerando que as principais reivindicações de igualdade entre os sexos foram já satisfeitas" (AMARAL; MACEDO, 2005, p. 153).

Certamente não seria possível discutir neste artigo, dados os objetivos traçados, as diversas e múltiplas nuances do feminismo - ou dos feminismos - que têm abarcado a contemporaneidade. Interessa, de fato, elucidar alguns expoentes que surgem dentro do "pós-feminismo" a fim de se compreender em que medida os chick lits podem realmente ser 
considerados como expressão efetiva de um movimento que traz em seu bojo um ideário libertário para as mulheres.

Nesse sentido, segundo Ainhoa Flecha (2010), num artigo dedicado ao estudo do feminismo do século XXI, de uma forma geral, a terceira onda feminista poderia ser classificada em duas correntes: pós-modernas e dialógicas. Assim,

No que tange às correntes pós-modernas atuais, considerarmos aquelas que incidem sobre o conceito diferença e aqueles que questionam o pensamento binário (masculino/feminino) e propõem a dissolução das categorias de gênero. Ambas são baseadas nos estudos feitos por autores como Foucault (2000) e Derrida (1998), entre outros. Nas correntes dialógicas, incluímos aqueles que defendem um feminismo com base na igualdade das diferenças para ser capaz de incluir todas as vozes, especialmente aquelas tradicionalmente ausentes em fóruns feministas (grupos culturais das mulheres, donas de casa, mulheres sem instrução, as mulheres do terceiro mundo etc.)" (tradução nossa). (FLECHA, 2010, p. 327). ${ }^{2}$

$\mathrm{Na}$ esteira dos estudos de Flecha, percebe-se uma faceta da terceira onda feminista ligada ao veio dialógico que se intitulou girlie, que seria um movimento encabeçado por jovens mulheres, desligado de conceitos profundos e menos acadêmico em sua origem.

O movimento girlie teve início nos Estados Unidos durante os anos 1980 e 1990. Uma de suas principais impulsionadoras foi Rebecca Walker (1969). Conforme Flecha (2010) e Karp e Stoller (1999), autoras como Walker e outras adeptas desse movimento, em sua essência, apoiam um feminismo do tipo do it yourself (DIY), baseando-se na ideia de que o feminismo é o que cada mulher quer fazer dele e, portanto, há tantos feminismos quanto mulheres no mundo. O problema, segundo as autoras (FLECHA, 2010; KARP; STOLLER, 1999), é que a

2 "Bajo corrientes postmodernas tenemos en cuenta aquellas que se centran en el concepto de diferencia así como aquellas que cuestionan el pensamiento binario (hombre / mujer) y proponen la disolución de las categorías de género. Ambas se basan en los desarrollos realizados por autores como Foucault (2000) o Derrida (1998), entre otros. En las corrientes dialógicas incluimos aquellas que defienden un feminismo basado en la igualdad de diferencias que sea capaz de incluir todas las voces, especialmente aquellas tradicionalmente ausentes en los foros feministas (mujeres de grupos culturales, amas de casa, mujeres sin estudios, mujeres del tercer mundo, etc.) " 
individualização proposta pelo DIY elimina a capacidade de luta por objetivos e causas comuns às mulheres, diminuindo o poder e a força da luta coletiva. Um outro ponto crítico desse movimento seria a exaltação da feminilidade em oposição ao modelo anterior de "boa feminista", que rechaçava toda atitude que pudesse remeter ao tipo "feminina". Assim, defendem o direito de usar maquiagem, sapatos altos, tomando como símbolo desse comportamento a cor rosa (FLECHA, 2010).

Em todo caso, a principal crítica ao feminismo girlie (ou DIY) refere-se ao fato de que ele se tornou um movimento de meninas consumistas "de classe média e alta que não conhecem os problemas que enfrentam a maioria das mulheres jovens, sendo que não lhes interessa combater a exclusão social, evitando qualquer projeto político" (tradução nossa). ${ }^{3}$ (FLECHA, 2010, p. 328).

A pergunta que cabe diante do exposto é: por que o pós-feminismo tem recebido tais contornos? Em virtude das demandas liberais das sociedades contemporâneas, é interessante considerar os movimentos sociais, como já foi dito, dentro de um contexto de realidade sem fronteiras, de capitalismo global, admitindo, assim, que são marcados pela difusão massiva de informações. Nesse âmbito, a mídia ou os diversos meios de comunicação podem ser compreendidos como centros reguladores de poder (GOFFMAN, 2009) ou como instrumentos centrais de sua propagação. No que se refere ao feminismo da terceira vaga, ele tem assimilado estereótipos ligados ao feminino que são veiculados por diversos meios de comunicação, não tanto para combatê-los, mas principalmente para reproduzi-los como algo que pode ser controlado e usado a favor das mulheres.

Em suma, o feminismo do tipo DIY não se realiza sem a mídia, que veicula paradigmas de comportamento para as garotas que desejam ter a sua imagem associada à de uma mulher "dona de si e bem-sucedida". Em outras palavras, o que se observa é que questões históricas relativas à luta das mulheres por um espaço de igualdade foram paulatinamente

3 "Clases medias y altas que no conocen los problemas a los que se enfrentan la mayoría de las mujeres jóvenes y a las que no les interesa combatir la exclusión social, evitando cualquier proyecto político". 
sendo assimiladas pelos mais diversos meios de comunicação, esvaziadas de conteúdo e transformadas em pauta de consumo. O feminismo passou a ser, nessa esfera, algo que pode ser realizado pela própria jovem desde que ela queira ou desde que assuma alguns tipos de conduta considerados "femininos".

Como se pode notar, alguns conceitos vão entrando "em moda" e sendo incorporados ao léxico de matriz feminista, numa espécie de aglutinação de ideias e de conceitos que são, em sua essência, opostos e antitéticos. Esses conceitos veiculam modos de ser que conotam às meninas uma sensação de liberdade e poder. Disseminam modelos ideais de qual mulher elas poderão ser, instituindo, assim, identidades carregadas de estereótipos. Então, assumir a bandeira feminista passou a ser, em palavras mais simples, mais acessível do que no passado. Afinal, uma girlie é uma jovem poderosa que pode fazer as suas escolhas e agir segundo os seus próprios princípios, algo nunca antes tão facilmente sonhado em gerações anteriores.

Por ser tangido sem amarras acadêmicas, mas livremente inspirado nas ideias libertárias de autoras feministas como Chimamanda Ngozi Adichie (1977), essa nova bandeira está sendo erguida não por filósofas, antropólogas, mas por pops stars, por exemplo. Recentemente, a cantora inglesa Adele, numa entrevista à revista Rolling Stone (ago. 2015), afirmou ser feminista e acreditar que todos deveriam ser tratados da mesma forma. Já Beyoncé, na ocasião de sua premiação no Video Music Awards (VMA) de 2014, promovido pela MTV, aproveitou para projetar o feminismo enquanto apresentava "Flawless", cuja letra traz a fala da escritora nigeriana Chimamanda. Ao lançar o último álbum, autointitulado, trouxe à tona a questão do feminismo como um modelo de atitude para as garotas estadunidenses. Diversas músicas desse álbum têm um teor combativo, lançando a ideia de que garotas podem ser fortes e independentes, desvirando a ideia de "mulher-objeto" do avesso. Note-se, a título de exemplo, um excerto da música "Run the world", do álbum em pauta: 
1. Run The World (Girls)

2. Girls, we run this mutha! (3x)

3. Girls!

4. Who run the world?

5. Girls! $(3 x)$

6. $[\ldots]$

7. Some of them men think they freak this

8. Like we do

9. But no they don't

10. Make your check come at they neck

11. Disrespect us?

12. No they won't $[\ldots]$

A música de Beyoncé é veiculada num contexto em que garotas norte-americanas, sobretudo negras, reivindicam o poder. A pop star surge nesses versos como porta-voz de um ideário feminista. Entretanto, ao lado dela, há uma máquina que movimenta a indústria da moda, dos costumes, da beleza. Beyoncé personifica diversos padrões estéticos impostos às mulheres, mas se assume feminista. Isso pode incomodar as feministas mais acadêmicas, mas a atitude da pop star é válida? De qualquer forma, a artista integra e representa o feminismo DIY. Por meio de sua influência, mais e mais garotas estadunidenses vão querer imitá-la, inclusive reproduzindo a sua visão de mundo. Para além disso, usarão sua marca de cosméticos, de roupas, e vão fazer sacrifícios corporais para alcançar tal modelo de beleza.

Em todo caso, o que as farão se sentir garotas poderosas é a força que é transmitida nos símbolos que representam o universo feminino girlie, como o uso de determinadas cores de batom, sobretudo variações de rosa (matte), maquiagens, tipos de roupas, sapatos. Esses símbolos funcionam como instrumentos de poder feminino dentro da terceira onda feminista.

4 “Comandam o Mundo (Garotas): Garotas, nós comandamos essa merda! (3x) / Garotas! / Quem comanda o mundo? / Garotas! (3x) [...] / Alguns homens pensam que detonam nisso / Como nós fazemos / Mas não, eles não detonam / Joguem seu dinheiro na cara deles / Nos desrespeitar? / Não, eles não irão [...]” (tradução nossa). 
Portanto, alguns pressupostos do pós-feminismo, afinados aos discursos midiáticos, segundo McRobbie (2004) e Baumgardner e Richards (2000), não estão exatamente inventando comportamentos, tendências ou valores, mas decidindo a qual dar visibilidade, legitimidade e importância. A partir daí, produzem apelos eficientes e ditam estilos de vida para vender produtos e modelos de beleza e comportamento atrelados à indústria de consumo.

Se os diversos meios de comunicação divulgam tendências e valores ao par dos contextos de produção, obviamente a literatura de massa também os assimila e os redistribui. Um caso expressivo da literatura de massa voltada para o público feminino são os chick lits e seus subgêneros, como é o caso do teen chick lit.

$\mathrm{O}$ chick lit surgiu, em língua inglesa, em meio à vaga do pós-feminismo nos anos 90 do século XX. No Brasil, esse tipo de literatura tem sido vulgarmente denominado de "literatura de mulherzinha" ou mesmo "literatura cor-de-rosa", classificações problematizadas por autoras como Zahidé Lupinacci Muzart (2007) e que, certamente, mereceriam ser discutidas num artigo à parte. De qualquer forma, trata-se de uma literatura escrita por mulheres que tem como público-alvo mulheres de meia-idade ou jovens (LEIRO, 2010). Acerca da origem do gênero:

Na esteira da publicação e do sucesso comercial de O Diário de Bridget Jones (1996), de Helen Fielding, até o final da década de 1990, o chick lit havia se estabelecido como um tipo de romance escrito por mulheres (em grande parte) para mulheres que descreve a vida, os amores, as provações e tribulações de protagonistas predominantemente jovens, solteiras e urbanas" (tradução nossa). (GORMLEY, [201-?]). ${ }^{5}$

Destarte, um dos principais objetivos do chick lit é o entretenimento do tipo "sessão da tarde", que tem por finalidade o divertimento. De uma forma geral, podem ter como protagonistas mulheres solteiras ou

5 "In the wake of the publication and commercial success of Helen Fielding's (1996) novel Bridget Jones's Diary, by the end of the 1990s the category and term chick lit had become established to describe novels written by women, (largely) for women, depicting the life, loves, trials and tribulations of their predominantly young, single, urban, female protagonists". 
aspirantes ao casamento. O chick lit pode tratar subliminarmente de diversas situações que abrangem o cotidiano feminino, como o sucesso escolar, acadêmico ou profissional etc.; casamento; divórcio. Entram em cena os conturbados relacionamentos familiares e amorosos; problemas relacionados ao corpo, como obesidade, culto à boa forma ou mesmo a pressão social em torno da maternidade. São livros, em todo caso, de confidencialidades, que têm como matéria principal os dilemas, as dúvidas, as inseguranças e os problemas mais diversos vivenciados por mulheres. Segundo Leiro (2010):

Os romances desse gênero salientam que as mulheres estão mais preocupadas em partir em busca de um marido que lhes possa dar filhos do que na manutenção de sua carreira profissional. Depois de alcançar a estabilidade, os romances chick lit trazem uma leitura invertida da mulher contemporânea e transforma o mal-estar daquelas afetadas pela mítica feminina (FRIEDAN) em uma relação inversa: se as mulheres dos anos 50 se sentiam "incompletas", infelizes com os seus limitados papéis de esposa e mãe, as protagonistas do chick lit estão se sentindo "inacabadas" por não terem um marido e filhos. Falta-lhes estarem dentro de uma estrutura legítima - a família nuclear/burguesa. A lógica permanece binária e oposicional.

Em termos específicos de gênero, como a autora procura chamar atenção, o chick lit não atua como adjuvante das mulheres, na medida em que reforça modelos que são muito comuns dentro de uma estrutura social patriarcalista, aproximando-se, dessa forma, de outros tipos de romance, como os que eram comumente chamados de "cor-de-rosa". Então, onde reside a diferença desse tipo de literatura em relação àquela literatura feita para mulheres? O chick lit acabou chamando atenção dos estudos culturais em sua ramificação pós-feminista por possuir características que o diferenciam dos romances do tipo "Sabrina”. Suzanne Ferriss e Young Mallory, no capítulo introdutório do livro Chick lit: The 
new woman's fiction (2006), tratam o chick lit como "uma forma de ficção feminina que tem por base o sujeito, a personagem, o público e o estilo narrativo" (tradução nossa) ${ }^{6}$ (FERRISS; MALLORY, 2006, p. 3). Enquanto o romance cor-de-rosa apresentaria dramas relativos ao universo feminino com toda a carga de estereótipos comuns a esse universo sem necessariamente ser escrito e protagonizado por mulheres, o chick lit avança para um terreno mais interessante na medida em que é produzido dentro de um contexto de liberdade de escrita das mulheres, mas pondo em causa, muitas vezes, pelos seus enredos de teor patriarcal, o poder de escolha feminino diante das mais diversas circunstâncias.

A crise que os romances chick lit apresenta da mulher adulta, urbana, contemporânea parece revelar os resquícios de uma sociedade que pensa nos moldes patriarcais, mas que desistiu de partir para o embate frontal com as feministas e percebeu uma arma poderosa para destruir as conquistas das mulheres sem aparecer como algoz: a linguagem. Por sua polissemia, seu deslizamento semântico e suas multifaces, a linguagem se torna peça fundamental (e não é de agora) de um jogo de poder muito mais complexo, dadas as tecnologias, que só através de um dispositivo de crítica igualmente sustentado pela linguagem poderia identificar as nuances das relações de força presentes nos discursos (LEIRO, 2010).

Para algumas autoras do pós-feminismo, como Stephanie Harzewski (2011), dentro da ficção chamada de "pós-moderna”, o chick lit não deixaria de ter sua relevância por fornecer um portal de acesso às políticas de gênero contemporâneas e a questões de valor cultural. Em seu livro Chick Lit and Postfeminism (2011), a autora dedica sustentada análise literária e feminista a suas origens, seu desenvolvimento e sua importância, conforme sublinha também Suzanne Ferriss (2011).

Conforme Sarah Gormley (201-?), apesar de serem evidentes a popularidade e o estabelecimento dos chick lits como um fenômeno editorial, esses romances "Tem provocado reações intensas e opostas. Para os fãs [do gênero], o chick lit reflete as experiências de mulheres jovens

6 "A form of woman's fiction on the basis of subject matter, character, audience, and narrative style". 
contemporâneas" (tradução nossa). ${ }^{7}$ Entretanto, ainda segundo Gormley (201-?), para os detratores do gênero, "esses romances são formulações estereotipadas, insípidas e, além disso, antifeministas, firmemente interessados em (re)colocar as mulheres dentro da esfera privada do lar e do coração" (tradução nossa). ${ }^{8}$

$\mathrm{Na}$ esteira dos estudos aqui expostos, os quais procuram problematizar o chick lit em termos de questões relativas à emancipação feminina, será tratado a seguir, mais especificamente, o teen chick lit, tomando como ponto de partida para reflexão o livro $O$ diário da princesa, de Meg Cabot.

\section{O diário da princesa, de Meg Cabot, e os estigmas de gênero}

Meg Cabot é uma autora estadunidense muito conhecida pel'O diário da princesa (o primeiro da série, publicado originalmente no ano 2000, já está em sua $34^{a}$ edição no Brasil). A autora, referência no gênero chick lit, tem quase 80 títulos lançados entre séries voltadas para adultos, jovens e pré-adolescentes, com mais de 25 milhões de cópias vendidas. Por aqui, seus livros já venderam mais de 1,5 milhão de exemplares (MEG CABOT..., 2015). Em O diário da princesa, conhece-se a história de Mia Thermopolis, uma jovem na faixa dos 14-15 anos que vive em Manhattan. A protagonista do romance mora com sua mãe, uma artista plástica com a qual

ele [o pai de Mia] nunca se casou [...]. Minha mãe diz que isso aconteceu porque, na época, ela rejeitava os costumes burgueses de uma sociedade que nem mesmo aceitava as mulheres como iguais aos homens e se recusava a reconhecer os direitos dela como pessoa (CABOT, 2014, p. 35).

O discurso de Mia transmite, inicialmente, a ideia de que sua mãe é uma mulher independente tanto emocional quanto financeiramente.

7 "Have provoked intense and oppositional responses. For the fans, it is claimed that chick lit reflects the experiences of contemporary young women".

8 "These novels are formulaic, vapid, and, moreover, anti-feminist, firmly (re)locating women within the private sphere of hearth and heart". 
No entanto, a própria adolescente irá, ao longo da narrativa, contestar o comportamento de sua progenitora - uma mulher razoavelmente intelectualizada, uma "artista boêmia” (CABOT, 2014, p. 45), por não corresponder efetivamente à imagem de mulher independente que sempre tentou mostrar à filha. Mia não concorda com o comportamento um tanto displicente da mãe, seja em relação às obrigações com a casa - como ir ao supermercado -, seja com as contas a pagar - como se observa pelas anotações no próprio diário da adolescente, por exemplo: "COISAS PARA FAZER: 8. Aluguel de outubro (confirmar se mamãe depositou o cheque de papai!!!) [...] 2. Fazer mamãe depositar o cheque de papai" (CABOT, 2014, p. 14, 27) ou

Papai repetiu essas palavras para minha mãe. Ouvi ela resmungar alguma coisa em resposta. Ela sempre resmunga quando lembro a ela que tem que entregar quadros em uma certa data. Mamãe gosta de trabalhar quando as musas dão uma ajudinha. Uma vez que papai paga a maioria das contas, isso geralmente não é problema, mas também não é uma maneira muito responsável de um adulto se comportar, mesmo que seja uma pintora (CABOT, 2014, p. 51).

Fica patente, assim, que ambas, mãe e filha, são sustentadas pelo pai de Mia, embora a mãe trabalhe em seu estúdio de artes a fim de garantir sua independência financeira. O que se nota é uma reconfiguração do patriarcalismo, que, como é válido lembrar, se sustenta “[...] pela autoridade, imposta institucionalmente, do homem sobre mulher e filhos no âmbito familiar" (CASTELLS, 2001, p. 169).

O pai de Mia, dessa forma, também se enquadra num paradigma de masculinidade socialmente desejável. Ele vive em Genovia, um país fictício situado entre a França e a Itália cujos habitantes não pagam impostos, muito semelhante a Mônaco, em razão de também ser um principado. Ele vê a filha esporadicamente, funcionando para ela mais como um provedor das finanças - na verdade, Mia tem pouca intimidade com o pai, com quem costuma passar apenas as férias de verão no castelo francês de Grandmère, a avó paterna, em Miragnac. 
A vida particular de Mia, exposta no diário, reflete o que os contextos sociais e culturais ainda mantêm do patriarcalismo. Outro exemplo disso seria o tratamento dado pelo pai às namoradas "de verão", que são, para ele, como objetos descartáveis:

$[\ldots]$ sempre tem uma nova namorada [...]. No verão, quando vamos para o castelo de Grandmère na França, ele sempre leva a moça da vez. Elas ficam sempre babando com as piscinas, as cachoeiras, a cachoeira, os 27 quartos, o salão de baile, a adega, a fazenda e a pista de pouso. Uma semana depois, manda a moça passear (CABOT, 2014, p. 35).

Essa nova reconfiguração do patriarcalismo parece prever exatamente algum tipo de liberdade de escolha e empoderamento feminino, ao menos até o ponto em que tudo fique sob controle. Essas garotas decidem onde e com quem querem estar, podem até estar num castelo usufruindo do conforto e da riqueza; podem servir e usar o sexo como prazer apenas por um verão, mas a decisão final de quem fica onde e com quem é do sujeito masculino, que "uma semana depois, manda a moça passear”. O poder exercido é do homem sobre a mulher, e

[...] para que essa autoridade possa ser exercida, é necessário que o patriarcalismo permeie toda a organização da sociedade, da produção e do consumo à política, à legislação e à cultura. Os relacionamentos interpessoais e, consequentemente, a personalidade também são marcados pela dominação e violência que têm sua origem na cultura e instituições do patriarcalismo (CASTELLS, 2001, p. 169).

Ainda acerca do pai de Mia, é válido ressaltar que ele é um aristocrata que governa um pequeno país da Europa por herança, um homem também frustrado, inacessível, deprimido, segundo considera Mia, em decorrência de um câncer de testículo que lhe tirou as possibilidades de novamente ser pai.

Como o problema todo gira em torno exatamente da falta de um herdeiro do sexo masculino, o que faz com que o pai de Mia seja obrigado a fazer dela a próxima herdeira do trono, a adolescente terá de se adaptar a uma nova vida e aprender a ser princesa. O livro mexe com o 
imaginário de muitas jovens ao tratar de um conto de fadas que aconteceu com uma garota "comum” de Nova York. Mia, então, precisará se transformar em uma verdadeira princesa, ter aulas de etiqueta com a rígida avó, com quem não tem muitas afinidades, e até mesmo carregar um guarda-costas a tiracolo. Isso tudo em meio ao auge da adolescência.

Lições de como ser princesa.

Não estou brincando. Tenho que ir direto de minha aula de revisão de álgebra para o Plaza, a fim de tomar lições de princesa com minha avó. [...] Papai diz que não tenho escolha [...]. Disse que eu havia assinado o compromisso, então era obrigada a tomar aulas de princesa como parte de meus deveres como herdeira (CABOT, 2014, p. 111).

A personagem não queria levar a sério a questão de tornar-se princesa, mas é forçada a fazê-lo por não ter alternativas. Dessa maneira, Mia vai recebendo, dia após dia, as lições de Grandmère: "Amanhã, você vai usar meias de nylon. Não malha. Não meias pelos joelhos. Você já está crescida demais para malha e meias pelos joelhos. E vai usar os sapatos da escola, e não tênis. Vai arrumar os cabelos, usar batom e pintar as unhas" (CABOT, 2014, p. 117). Essas lições pretendem ensinar à garota modos adequados de ser e de se comportar.

Mia não era um modelo de feminilidade, não para os padrões de Grandmère. Não usava adereços femininos, como meias finas, ou mesmo maquiagem, era alta, desajeitada e roía as unhas, seus cabelos eram desalinhados; não era como as demais garotas no que tange aos desejos consumistas, era simpatizante do Greenpeace. Ser diferente, nesse sentido, passou a ser inadequado e Mia viu-se obrigada a moldar-se ao novo paradigma de comportamento que lhe estava sendo imputado.

A grande sacada da autora reside justamente em construir uma personagem que não se enquadraria nos modelos de gênero, corpo e beleza socialmente ideais, o que poderia criar certa identificação por parte de diversos leitores, para depois colocá-la justamente dentro de um padrão e assim formar uma rede de empatia com o público leitor. 
Na trama de Meg Cabot, a adaptação a essa nova identidade causa sofrimento a Mia.

[...] É meio difícil, quando todas aquelas pessoas bonitas, elegantes, dizem como a gente parece bem usando isto e como nossas maçãs do rosto ganham vida com aquilo, a gente se lembrar que é feminista e ambientalista e que não acredita em usar maquiagem ou produtos químicos que sejam nocivos ao planeta [...]. Mas não me sinto feliz. Nem um pouquinho. Grandmère está feliz [...] com minha aparência. Porque eu não pareço nada com Mia Thermopolis. Mia Thermopolis nunca teve unhas. Mia Thermopolis nunca usou maquiagem, sapatos Gucci, saias Chanel ou sutiã Christian Dior [...]. Eu nem sei mais quem sou. Ela está me transformando em outra pessoa (CABOT, 2014, p. 135-136).

A crise de identidade vivida por Mia nos remete a um anteprojeto feminista. Ela precisa representar um papel para o qual não se acha preparada. A tensão da narrativa reside basicamente em sua não aceitação da nova identidade, atrelada a estereótipos de gênero, corpo, comportamento e beleza.

No entanto, o fato é que Mia irá se acomodar, se enquadrar ao padrão "princesa”, aceitando usar os adereços que deviam ser mais pertinentes à nova vida: "Grandmère disse que, quando eu for jantar com eles na noite de sexta-feira, devo levar um presente e usar meus mocassins Gucci” (CABOT, 2014, p. 183). Portanto, no decorrer da narrativa, ela vai mudando gradativamente de comportamento, indo da não aceitação e resistência a certo tipo de conformismo. Isso vai ocorrer mais propriamente quando Mia acaba por ter a sua imagem veiculada na primeira página do New York Post com a seguinte chamada: "Princesa Amelia e, em letras menores, A autêntica Realeza Nova-Iorquina" (CABOT, 2014, p. 187).

A partir desse momento, Mia, que antes se sentia desprezada pelos garotos de seu colégio por ser "alta, uma girafa [...] nenhuma beldade" (CABOT, 2014, p. 189), percebe que "de repente, [ficou] muito popular” (CABOT, 2014, p. 194), passando inclusive a ser paquerada pelo 
rapaz mais interessante do colégio, que a convida para ir com ele a um baile:

Bem, aqui estou eu, sentada, usando o meu vestido novo, meus sapatos novos, minhas unhas novas, minha meia-calça nova, com minhas pernas e axilas devidamente depiladas, meu novo cabelo, meu rosto maquiado profissionalmente, são sete horas, não há sinal de Josh [...]. Graças a Deus o interfone tocou nesse momento. É ele (CABOT, 2014, p. 253).

Mia, afinal, não ficará com Josh, que queria apenas se aproveitar da fama dela. Ela dá a volta por cima e escolhe outro garoto. Agora, a protagonista já pode escolher com quem quer ficar. Tudo começa a dar certo. A narrativa não termina num grande palácio, mas numa festa onde Mia finalmente namora Michael, amor antigo, irmão mais velho de Lilly, sua melhor amiga. Ele, um rapaz comum, menos popular, mas de quem ela sempre gostou, cuja qualidade predominante é a inteligência, ao contrário do outro pretendente, que era apenas "bonito". A protagonista sim já é outra, uma princesa: "pensei que realmente sou uma garota muito feliz. As coisas pareceram muito ruins durante algum tempo, mas não é engraçado como tudo se resolve no fim” (CABOT, 2014, p. 281). E happy end. O que prevalece no arremate da história é a imagem ideal de uma mulher numa garota que sabe se vestir e é educada para agradar, que representa bem uma posição aristocrática e um padrão de beleza.

Para Naomi Woolf (1992), esses paradigmas de corpo, beleza e comportamento desejados para o feminino não meramente representam o objeto, a pessoa ou o evento que ilustram, mas trazem antes significados mais profundos, nem sempre identificados facilmente. Na verdade, enquanto essas imagens podem representar empoderamento e atitude girlie, em contrapartida, contribuem para o desmerecimento do feminismo e, consequentemente, para o reforço do mito de beleza, construído, em tese, social e culturalmente contra as mulheres. 


\section{Considerações finais}

O livro de Meg Cabot é um exemplo do gênero chick lit ou do teen chick lit, ou seja, de um tipo de literatura que é produzido dentro da ficção de autoria feminina que tem como pauta comum questões relativas ao universo das jovens mulheres contemporâneas. A leitura do romance permitiu entrevê-lo como um romance de enredo leve, situado na cultura de massa, procurando mostrar a imagem de garotas bem informadas, independentes e cultas.

Nesse sentido, algumas teóricas feministas atreladas à terceira vaga procuram considerar o chick lit como um tipo de literatura pós-feminista por expor as mulheres não mais como vítimas de uma sociedade opressora de gênero e por ser uma ficção voltada para as experiências femininas, como namoro, beleza, profissão, ativismo, sexo etc. $\mathrm{O}$ mesmo se aplicaria ao teen chick lit.

Entretanto, essa literatura estaria, em contrapartida, revestida de conteúdos opressores de gênero e ligados à indústria de consumo. Como pôde ser observado, interessa ao teen chick lit apresentar meninas protagonistas "bem-vestidas e com boa aparência" que são, contudo, críticas e conscientes da realidade nos contextos culturais em que estão inseridas. A questão é que essas mesmas jovens também representam "um lugar" do qual emitem a sua voz e seus atos. Tanto Mia, a personagem principal d'O diário da princesa, quanto as protagonistas dos teens chick lits são, em geral, brancas, heterossexuais, de classe média alta, em contextos misóginos, patriarcais, conforme enfatizam Suzanne Ferriss e Young Mallory (2006). Ao que tudo indica, os dramas vividos pelas protagonistas dos teen chick lit representam uma cultura de gênero que parece não estar pronta para o empoderamento feminino, além de excluir questões de sexualidade, classe social e raça ao privilegiar apenas os padrões normativos ideias dessas categorias.

Para Stuart Hall (1997, p. 33), toda prática social tem uma dimensão cultural e um caráter discursivo: "consequentemente, a cultura é uma das condições constitutivas de existência dessa prática”. Em relação à adolescência, pensando em termos de identidade cultural e constituição 
de sujeitos como construtos sociais (HALL, 2005), pode-se aventar que a construção das identidades se articula aos discursos que são veiculados e sustentados por diversos artefatos culturais construídos, muitas vezes, exatamente para esse público. No que se refere às jovens mulheres, dentre tais artefatos, o romance do tipo teen chick lit, ao veicular de forma massiva uma gama enorme de informações sobre os mais variados assuntos, também disseminam modos de ser e até o que elas devem gostar e como devem proceder.

Portanto, ao se tomar como exemplo de análise a jovem Mia, percebeu-se que, se, no início do romance, ela se achava fora dos padrões por ser alta, magra e com pés grandes, por roer unhas, por ter cabelos desalinhados e, principalmente, por questionar o consumismo de suas colegas de escola, ao fim, a protagonista acaba por se enquadrar num modelo de comportamento, passando a ter uma imagem socialmente aceita em favor de uma nova identidade: a de ser "princesa". Atrelado a isso vieram a conquista do garoto dos sonhos, a admiração de outras colegas de escola, a aprovação da mídia.

Uma vez que, como se sabe, a leitura de um romance não se esgota no seu consumo, mas desdobra-se em práticas de impacto social, a questão que fica subliminarmente é: quantas meninas não podem se sentir como Mia? Afinal, se uma garota comum pôde se tornar uma princesa "dona de si" em poucos meses, qualquer girlie pode sentir esse "empoderamento", bastando lições de etiqueta, makes adequados e roupas de marca. É nesse sentido que, dentre a gama de interpretações e considerações possíveis, $\mathrm{O}$ diário da princesa enquadra-se como um produto comercial cujo teor ligado à esfera das lutas de emancipação feminina atua em favor do mercado de consumo.

Ao cabo desse texto, a impressão que se tem é que o engajamento proposto pelo feminismo DIY, do qual o chick lit (e seus subgêneros, como o teen chick lit, por exemplo) tornou-se expressão, pressupõe justamente o reforço de normas simbólicas e valores morais ligados a formas de conduta que há anos as feministas acadêmicas têm questionado. Dito de uma outra maneira, uma leitura mais atenta, a contrapelo, desse tipo 
de romance revela um realinhamento dessa "nova autonomia feminina" numa sociedade cujo patriarcalismo autoriza e regula o comportamento feminino. Se, de um lado, contribui para a disseminação da ideia de empoderamento da mulher a partir de protagonistas críticas, independentes e ativas, de outro, reforça estigmas de comportamento e de beleza que atuam justamente contra esse mesmo empoderamento.

\section{Referências}

ADORNO, T.; HORKHEIMER, M. A indústria cultural - o iluminismo como mistificação das massas. In: ADORNO, T. Indústria cultural e sociedade. São Paulo: Paz e Terra, 2002.

AMARAL, A. L.; MACEDO, A. G. (Orgs.). Dicionário da crítica feminista. Porto: Afrontamento, 2005.

BAUMGARDNER, J.; RICHARDS, A. Manifesta: Young Women, Feminism, and the Future. Nova York: Farrar, Straus and Giroux, 2000.

BEAUVOIR, S. de. O segundo sexo. Trad. Sérgio Milliet. 4. ed. São Paulo: Difusão Europeia do Livro, 1970. 2v. (Originalmente publicado em 1949).

CABOT, M. O diário da princesa. Rio de Janeiro: Galera Record, 2014.

CASTELLS, M. O poder da identidade. Rio de Janeiro: Paz e Terra, 2001.

FERRISS, S. Review: Chick Lit and Postfeminism. Journal of popular romance studies, 2.1, 2011. Disponível em: http://jprstudies.org/wp-content/uploads/2011/11/JPRS2.1_ Ferriss_ReviewHarzewski.pdf. Acesso em: 23 mar. 2016.

.; MALLORY, Y. Chick lit: The new woman's fiction. Nova York: Londres: Routledge, 2006.

FLECHA, A. Las hijas de las feministas. El feminismo del siglo xxi: ¿declive o democratización? Revista de la Asociación de Sociología de la Educación, v. 3, n. 3, p. 325-335, 2010. Disponível em: https:/ojs.uv.es/index.php/RASE/article/view/8715. Acesso em: 20 jan. 2016.

GOFFMAN, E. A representação do eu na vida cotidiana. Rio de Janeiro: Vozes, 2009.

GORMLEY, S. Introduction. Working papers in the web. [201-?]. Disponível em: http:// extra.shu.ac.uk/wpw/chicklit/gormley.html. Acesso em: 23 mar. 2016.

HALL, S. A identidade cultural na pós-modernidade. Rio de Janeiro: DP\&A, 2005.

The work of representation. In: Representation - Cultural representations and signifying practices. Londres: SAGE, 1997. 
HARZEWSKI, S. Chik Lit and Postfeminism. Charlottesville: University of Virginia Press, 2011.

KARP, M.; STOLLER, D. The Bust Guide to the New Girl Order. Nova York: Penguin, 1999.

LEIRO, L. Impressões sobre a literatura chick lit. 2010. Disponível em: http://mulhereliteratura.blogspot.com.br/2010/05/impressoes-sobre-literatura-chicklit.html. Acesso em: 15 set. 2015.

MCROBBIE, A, Notes on Postfeminism and Popular Culture: Bridget Jones and the New Gender Regime. In: HARRIS, A. (Ed.). All About the Girl: Culture, Power, and Identity. Nova York: Routledge, 2004.

MEG CABOT, autora do best-seller O Diário da Princesa, vem ao Brasil em outubro. BBC News. Notícias. 29 ago. 2015. Disponível em: http://www.bbcnews.com.br/ noticia/157756-meg-cabot-autora-do-best-seller-o-diario-da-princesa-vem-ao-brasil-em-outubro.html. Acesso em: 14 mar. 2016.

MUZART, Z. L. Literatura de mulherzinha. Labrys, études féministes/estudos feministas, jan.-jun 2007. Disponível em: http://www.labrys.net.br/labrys1l/ecrivaines/zahide.htm. Acesso em: 4 abr. 2017.

ROLLING STONE, ed. 1.248, nov. 2015. Disponível em: http://www.brasilpost. com.br/2015/11/03/rolling-stone-adele-capa_n_8463608.html?ncid=fcbklnkbrhp mg00000004. Acesso em: 17 nov. 2015.

WOLF, N. O mito da beleza. Rio de Janeiro: Rocco, 1992.

\section{Sobre a autora}

Mestre e doutora em Letras pela Universidade de São Paulo. Pós-doutora em Literatura Portuguesa pela FFLCH/USP, com financiamento da Fundação de Amparo à Pesquisa do Estado de São Paulo. Membro do Grupo de Estudos de Literatura de Autoria Feminina (USP/CNPq) e do grupo de investigação das Relações entre Literatura e Jornalismo do Centro de Literaturas e Culturas Lusófonas e Europeias da Universidade de Lisboa (CLEPUL). Este trabalho é parte da pesquisa de pós-doutorado financiada pela CAPES em conjunto com a Universidade Presbiteriana Mackenzie.

Data de submissão: 24/05/2016

Data de aceite: $21 / 11 / 2016$ 